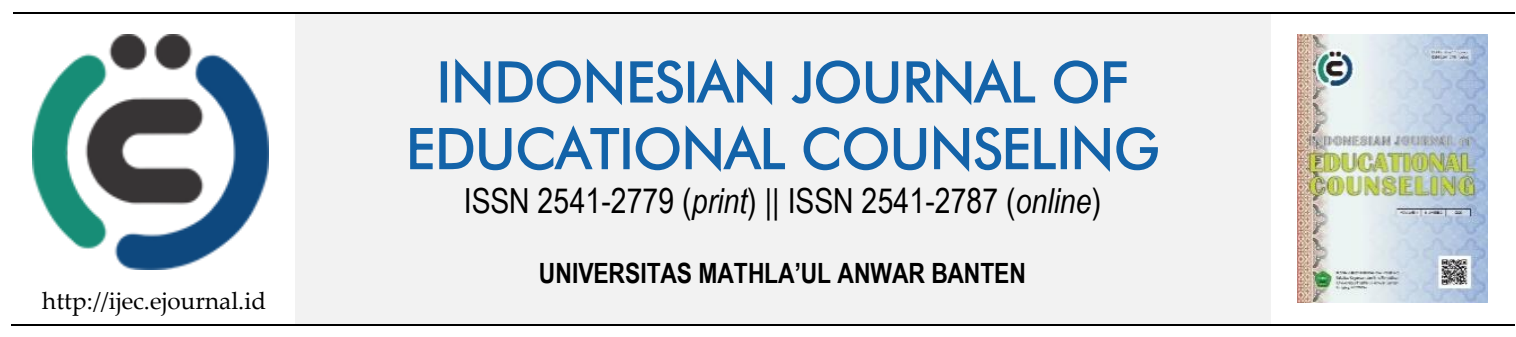

Research Based Article

\title{
Evaluasi Reaksi Terhadap Pelaksanaan Diklat Penguatan Kepala Sekolah di BPSDM Provinsi DKI Jakarta (Tinjauan berdasarkan Karakter Kepemimpinan Kepala Sekolah)
}

\author{
Neny Rahmawati ${ }^{1}$ \\ ${ }^{1}$ BPSDM Provinsi DKI Jakarta, Indonesia
}

\begin{tabular}{ll}
\hline Article History & ABSTRACT \\
\hline $\begin{array}{l}\text { Received: 05.03.2020 } \\
\text { Received in revised form: }\end{array}$ & EVALUATION OF THE REACTION TO THE IMPLEMENTATION OF \\
09.06 .2020 & STRENGTHENING SCHOOL PRINCIPAL IN BPSDM DKI JAKARTA \\
Accepted: 25.06 .2020 & PROVINCE. The strategic role of the headmaster in education requires the \\
Available online: 23.07 .2020 & implementation of the school principal strengthening. This study aims to see \\
& the results of the reaction evaluation of the participants of the strengthening \\
& school principal, held by the BPSDM DKI Jakarta province with the evaluation \\
& model of Kirkpatrick Level 1. The method used is a descriptive evaluative with \\
the survey method. The instruments used are questionnaires. Sampling with a & random sampling purpose technique and selected 90 participants from the total \\
& population of 900 people. The results showed an average of the participants' \\
& overall response to the faculty evaluation element of 3.61, so it could be stated \\
that the Participants had a very good perception of the whole teacher. The & average is obtained because the quality of module and quality of organizers \\
have been good, while the quality of facilities and infrastructure is very good. & The conclusion of this research is the response of participants in the \\
implementation of the school's strengthening training (MCC) is very good \\
towards the teacher evaluation element. So also the participants ' response to \\
the quality of the modules and organizers is good, and the response is excellent \\
to the facilities and infrastructure.
\end{tabular}

KEYWORDS: Kirkpatrick Evaluation, School Principal, Training.

DOI: $10.30653 / 001.202042 .141$

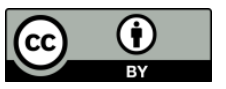

This is an open access article distributed under the terms of the Creative Commons Attribution 4.0 International License, which permits unrestricted use, distribution, and reproduction in any medium, provided the original work is properly cited. C) 2020 Neny Rahmawati.

\section{PENDAHULUAN}

Pendidikan memegang peranan yang sangat penting dalam menciptakan manusiamanusia yang berkualitas. Pendidikan juga dipandang sebagai sarana untuk melahirkan insan-insan yang cerdas, kreatif, terampil, bertanggung jawab, produktif dan berbudi pekerti luhur. Namun demikian kualitas pendidikan Indonesia tergolong rendah, hal ini dibuktikan dengan data berdasarkan laporan PISA (Programme for International Student Assessment) peringkat pendidikan Indonesia di dunia bertengger di urutan 62 dunia di

\footnotetext{
${ }^{1}$ Corresponding author's address: BPSDM Provinsi DKI Jakarta. Jl. Abdul Muis No. 66, RT. 04 RW. 03, Petojo Selatan, Gambir, Kota Jakarta Pusat, DKI Jakarta 10160, Indonesia. Email: unineny@ gmail.com
} 
bidang sains, 63 dunia di bidang matematika, dan 64 dunia di membaca. Masih di bawah Singapura, Vietnam, dan Thailand. PISA sendiri merupakan survei yang menguji kemampuan siswa berusia 15 tahun untuk tiga bidang, yakni membaca, matematika, dan sains. Survei ini diinisiasi oleh Organization for Economic Cooperation and Development (OECD) (Maya, 2020).

Terdapat banyak faktor yang menyebabkan pendidikan Indonesia rendah. Dari delapan standar pendidikan, kita hanya fokus pada standar proses, isi, dan kompetensi lulusan sebagai sumber masalah dalam pendidikan padahal standar lain yang berbasis manajerial pun (peran kepala sekolah) tidak kalah penting untuk kita perhatikan sebagai penyebab rendahnya pendidikan Indonesia. Hal ini menegaskan bahwa kualitas pendidikan tidak lepas dari peran kepala sekolah sebagai pemimpin. Kepala sekolah memiliki peran strategis dalam proses peningkatan mutu pendidikan. Kepala sekolah mempunyai tugas yang sangat penting di dalam mendorong guru untuk melakukan proses pembelajaran yang mampu menumbuhkan berpikir kritis, kreatif, inovatif, cakap menyelesaikan masalah, dan bernaluri kewirausahaan bagi siswa sebagai produk suatu sistem pendidikan. Lebih lanjut, kepala sekolah juga berperan menjadi faktor pendorong untuk mewujudkan visi, misi, tujuan, termasuk sasaran. Karena itu, kepala sekolah dituntut memiliki kemampuan manajemen dan kepemimpinan yang tangguh. Kepala sekolah jugaharus mampu memobilisasi sumber daya sekolah, perencanaan dan evaluasi program, kurikulum, pembelajaran, pengelolaan personalia, sarana dan sumber belajar, keuangan, pelayanan siswa, hubungan dengan masyarakat, dan penciptaan iklim kondusif.

Kualitas kepala sekolah yang menjadi penentu keberhasilan pendidikan sebetulnya sudah disadari oleh pemerintah. Hal tersebut terlihat dari diselenggarakannya diklat oleh lembaga Badan Pengembangan Sumber Daya Manusia (BPSDM) Provinsi DKI Jakarta yang mempersiapkan kepala sekolah-kepala sekolah terbaik. Sejalan dengan diterbitkannya Peraturan Menteri Pendidikan dan Kebudayan nomor 6 tahun 2018 tentang penugasan guru sebagai kepala sekolah, bagi para kepala sekolah dari level TK hingga SMA/SMK, baik sekolah negeri maupun swasta harus memiliki memiliki surat tanda tamat pendidikan dan pelatihan (STTPP). STTP ini merupakan bentuk nyata intervensi pemerintah dalam menciptakan program diklat penguatan agar para kepala sekolah dapat bekerja sesuai dengan standar yang ditetapkan (SAFITRI \& YUSIYAKA, 2020)

Program diklat penguatan kemampuan kepala sekolah sangat penting mengingat peran strategis kepala sekolah di dalam proses peningkatan mutu pendidikan. Melalui diklat ini diharapkan kepala sekolah dan calon kepala sekolah memiliki kompetensi dan dedikasi yang tinggi dalam memajukan pendidikan di Indonesia. Maka dari itu, dalam rangka menjalankan amanah konstitusi yang tertuang dalam UU Sisdiknas No 20 Tahun 2003, perlu ada kajian akademis yang mengevaluasi penyelenggaran diklat Penguatan Kepala Sekolah. Evaluasi ini bertujuan untuk melihat seberapa jauh keefektivasan dari penyelanggaran diklat tersebut, termasuk seberapa besar pengaruh diklat terhadap peserta. Pelaksanaan evaluasi terhadap diklat juga bertujuan untuk meningkatkan kinerja sumber daya manusia. Selain itu, diklat juga dapat memperbaiki masalah- masalah yang terjadi pada organisasi, baik organisasi belajar ataupun organisasi dari lembaga tersebut sehingga dapat diketahui apakahpelatihan yang telah dijalankan dapat mencapai sasaran dari tujuan yang telah ditetapkan.

Berdasarkan uraian di atas, maka peneliti mengambil judul "Evaluasi Reaksi Terhadap Pelaksanaan Diklat Penguatan Kepala Sekolah Di BPSDM Provinsi Dki Jakarta 
(Tinjauan Berdasarkan Karakter Kepemimpinan Kepala Sekolah)". Evaluasi dalam penelitian ini menggunakan model evaluasi empat level Kirkpatrick dan evaluasi ini difokuskan pada level 1 (Reaksi) Kirkpatrick, yaitu mengenai reaksi dan kepuasaan peserta dikla. Peneliti akan mengevaluasi sesuai dengan pedoman model evaluasi empat level Kirkpatrick. Metode yang digunakan dalam penelitian ini adalah metode evaluatif deskripti dengan metode survei. Melalui penelitian evaluasi penyelenggaraan diklat ini diharapkan dapat memberikan informasi terkait hasil yang diperoleh dan dapat dijadikan acuan dalam menentukan intervensi untuk penyelenggaraan diklat Penguatan Kepala Sekolah berikutnya.

\section{METODE}

Penelitian ini menggunakan pendekatan penelitian evaluatif deskriptif dengan metode survei. Metode evaluasi deskriptif adalah metode penelitian yang berusaha menggambarkan dan menginterpretasi objek sesuai dengan apa adanya (Sukardi, 2003). Sedangkan survei adalah menjaring data/informasi dengan menggunakan responden berupa sampel yang ditarik dari populasi (Wirawan., 2012). Pada penelitian ini akan mengevaluasi pelaksanaan diklat Penguatan Kepala Sekolah guna memperoleh informasi mengenai reaksi peserta diklat.

Populasi yang akan digunakan pada penelitian ini adalah seluruh para peserta yang mengikuti diklat Penguatan Kepala Sekolah dengan jumlah 900 orang. Sampel yang digunakan adalah seluruh peserta diklat. Sementara teknik pengambilan sampel menggunakan teknik purpose random sampling. Berdasarkan Rumus Slovin jumlah sampling yang dijadikan kriteria sampel telah dipilih 90 peserta oleh peneliti (Sugiono, 2015). Instrumen yang digunakan adalah Kuesioner/Angket. Teknik pengumpulan data dalam penelitian ini menggunakan Penyebaran Kuesioner/Angket. Model evaluasi yang akan digunakan adalah model evaluasi Kirkpatrick yang dikembangkan oleh Donald L. Kirkpatrick. Penelitian ini mengevaluasi reaksi peserta diklat Penguatan Kepala Sekolah dengan menggunakan model evaluasi 4 level Kirkpatrick yaitu level 1 Reaksi.

\section{HASIL DAN PEMBAHASAN}

\section{Hasil: Evaluasi Pengajar untuk Masing-masing Indikator}

\section{Indikator Penguasaan Materi}

Hasil evaluasi reaksi peserta terhadap seluruh unsur penilaian terhadap penguasaan materi tersebut dijelaskan pada Tabel 1. Pada skala interpertasi analisis data, secara keseluruhan item pernyatan menunjukkan nilai berada di antara skala 3.5-4. Sehingga dapat dinyatakan bahwa para peserta memiliki persepsi sangat baik dari Indikator Penguasaan Materi Pengajar.

Tabel 1. Penguasaan Materi

\begin{tabular}{ll}
\hline Pengajar & Penguasaan Materi \\
\hline Pengajar 1 & 4.00 \\
\hline Pengajar 2 & 3.96 \\
\hline Pengajar 3 & 3.83 \\
\hline Pengajar 4 & 3.67 \\
\hline Pengajar 5 & 4.00 \\
\hline Pengajar 6 & 4.00 \\
\hline
\end{tabular}




\section{Indikator Sistematika Penyajian}

Hasil evaluasi reaksi peserta terhadap seluruh unsur penilaian terhadap sistematika penyajian dapat dijelaskan pada Tabel 2. Pada skala interpertasi analisis data, secara keseluruhan item pernyatan menunjukkan nilai berada di antara skala 3.5-4, sehingga dapat dinyatakan bahwa para peserta memiliki persepsi sangat baik dari Indikator Sistematika Penyajian Pengajar.

Tabel 2. Sistimatika Penyajian

\begin{tabular}{ll}
\hline Pengajar & Sistematika Penyajian \\
\hline Pengajar 1 & 4.00 \\
\hline Pengajar 2 & 3.93 \\
\hline Pengajar 3 & 3.83 \\
\hline Pengajar 4 & 3.50 \\
\hline Pengajar 5 & 3.67 \\
\hline Pengajar 6 & 4.00 \\
\hline
\end{tabular}

\section{Kemampuan Menyajikan (Berorientasi HOST)}

Hasil evaluasi reaksi peserta terhadap seluruh unsur penilaian terhadap sistematika penyajian dapat dijelaskan pada Tabel 3. Pada skala interpertasi analisis data, secara keseluruhan item pernyatan menunjukkan nilai berada di antara skala 3.5-4, sehingga dapat dinyatakan bahwa para peserta memiliki persepsi sangat baik dari Indikator Kemampuan Menyajikan (Orientasi HOST) Pengajar.

Tabel 3. Kemampuan Menyajikan

\begin{tabular}{ll}
\hline Pengajar & Kemampuan Menyajikan \\
\hline Pengajar 1 & 4.00 \\
\hline Pengajar 2 & 3.85 \\
\hline Pengajar 3 & 3.92 \\
\hline Pengajar 4 & 3.50 \\
\hline Pengajar 5 & 3.67 \\
\hline Pengajar 6 & 4.00 \\
\hline
\end{tabular}

\section{Relevansi Materi dengan Tujuan}

Hasil evaluasi reaksi peserta terhadap seluruh unsur penilaian terhadap relevansi materi dengan tujuan dapat dijelaskan pada Tabel 4. Pada skala interpertasi analisis data, secara keseluruhan item pernyatan menunjukkan nilai berada di antara skala 3.5-4, sehingga dapat dinyatakan bahwa para peserta memiliki persepsi sangat baik dari Indikator Relevansi Materi Dengan Tujuan Pengajar.

Tabel 4. Relevansi Materi dengan Tujuan

\begin{tabular}{ll}
\hline Pengajar & Relevansi Materi dengan Tujuan \\
\hline Pengajar 1 & 4.00 \\
\hline Pengajar 2 & 3.91 \\
\hline Pengajar 3 & 3.92 \\
\hline Pengajar 4 & 3.50 \\
\hline Pengajar 5 & 3.67 \\
\hline Pengajar 6 & 4.00 \\
\hline
\end{tabular}




\section{Penggunaan Metode Pembelajaran}

Hasil evaluasi reaksi peserta terhadap seluruh unsur penilaian terhadap penggunaan metode pembelajaran dapat dijelaskan pada Tabel 5 berikut ini :

Tabel 5. Penggunaan Metode Pembelajaran

\begin{tabular}{ll}
\hline Pengajar & Penggunaan Metode Pembelajaran \\
\hline Pengajar 1 & 3.83 \\
\hline Pengajar 2 & 3.83 \\
\hline Pengajar 3 & 3.92 \\
\hline Pengajar 4 & 3.67 \\
\hline Pengajar 5 & 4.00 \\
\hline Pengajar 6 & 4.00 \\
\hline
\end{tabular}

Pada skala interpertasi analisis data, secara keseluruhan item pernyatan menunjukkan nilai berada di antara skala 3.5-4. Sehingga dapat dinyatakan bahwa para peserta memiliki persepsi sangat baik dari Indikator penggunaan metode pembelajaran.

\section{Penggunaan Media Pembelajaran}

Hasil evaluasi reaksi peserta terhadap seluruh unsur penilaian terhadap penggunaan metode pembelajaran dapat dijelaskan pada Tabel 6. Pada skala interpertasi analisis data, secara keseluruhan item pernyatan menunjukkan nilai berada di antara skala 3.5-4, sehingga dapat dinyatakan bahwa para peserta memiliki persepsi sangat baik dari Indikator penggunaan media pembelajaran.

Tabel 6. Penggunaan Media Pembelajaran

\begin{tabular}{ll}
\hline Pengajar & Penggunaan Media Pembelajaran \\
\hline Pengajar 1 & 3.92 \\
\hline Pengajar 2 & 3.85 \\
\hline Pengajar 3 & 3.83 \\
\hline Pengajar 4 & 3.50 \\
\hline Pengajar 5 & 3.67 \\
\hline Pengajar 6 & 4.00 \\
\hline
\end{tabular}

\section{Penggunaan Bahasa}

Hasil evaluasi reaksi peserta terhadap seluruh unsur penilaian terhadap penggunaan bahasa dapat dijelaskan pada Tabel 7.

Tabel 7. Penggunaan Bahasa

\begin{tabular}{ll}
\hline Pengajar & Penggunaan Bahasa \\
\hline Pengajar 1 & 3.83 \\
\hline Pengajar 2 & 3.91 \\
\hline Pengajar 3 & 3.83 \\
\hline Pengajar 4 & 3.67 \\
\hline Pengajar 5 & 3.67 \\
\hline Pengajar 6 & 4.00 \\
\hline
\end{tabular}


Pada skala interpertasi analisis data, secara keseluruhan item pernyatan menunjukkan nilai berada di antara skala 3.5-4, sehingga dapat dinyatakan bahwa para peserta memiliki persepsi sangat baik dari Indikator Penggunaan Bahasa Pengajar.

\section{Nada dan Suara}

Hasil evaluasi reaksi peserta terhadap seluruh unsur penilaian terhadap nada dan suara pengajar dapat dijelaskan pada Tabel 8.

Tabel 8. Nada dan Suara

\begin{tabular}{ll}
\hline Pengajar & Penggunaan Bahasa \\
\hline Pengajar 1 & 3.92 \\
\hline Pengajar 2 & 3.91 \\
\hline Pengajar 3 & 3.83 \\
\hline Pengajar 4 & 3.67 \\
\hline Pengajar 5 & 4.00 \\
\hline Pengajar 6 & 4.00 \\
\hline
\end{tabular}

Pada skala interpertasi analisis data, secara keseluruhan item pernyatan menunjukkan nilai berada di antara skala 3.5-4, sehingga dapat dinyatakan bahwa para peserta memiliki persepsi sangat baik dari Indikator Nada dan Suara Pengajar.

\section{Cara dan Ketepatan Menjawab Pertanyaan Peserta}

Hasil evaluasi reaksi peserta terhadap seluruh unsur penilaian cara dan ketepatan menjawab pertanyaan peserta dapat dijelaskan pada Tabel 9.

Tabel 9. Cara dan ketepatan menjawab pertanyaan peserta

\begin{tabular}{ll}
\hline Pengajar & $\begin{array}{l}\text { Cara dan Ketepatan Menjawab } \\
\text { Pertanyaan Peserta }\end{array}$ \\
\hline Pengajar 1 & 3.92 \\
\hline Pengajar 2 & 3.87 \\
\hline Pengajar 3 & 3.83 \\
\hline Pengajar 4 & 3.67 \\
\hline Pengajar 5 & 3.67 \\
\hline Pengajar 6 & 4.00 \\
\hline
\end{tabular}

Pada skala interpertasi analisis data, secara keseluruhan item pernyatan menunjukkan nilai berada di antara skala 3.5-4, sehingga dapat dinyatakan bahwa para peserta memiliki persepsi sangat baik dari Indikator Cara dan Ketepatan Menjawab Pertanyaan Peserta.

\section{Kemampuan Memotivasi Peserta}

Hasil evaluasi reaksi peserta terhadap seluruh unsur penilaian Kemampuan Memotivasi Peserta dapat dijelaskan pada Tabel 10. Pada skala interpertasi analisis data, secara keseluruhan item pernyatan menunjukkan nilai berada di antara skala 3.5-4, sehingga dapat dinyatakan bahwa para peserta memiliki persepsi sangat baik dari Indikator Kemampuan Memotivasi Peserta. 
Tabel 10. Kemampuan Memotivasi Peserta

\begin{tabular}{ll}
\hline Pengajar & Kemampuan Memotivasi Peserta \\
\hline Pengajar 1 & 4.00 \\
\hline Pengajar 2 & 3.85 \\
\hline Pengajar 3 & 3.92 \\
\hline Pengajar 4 & 3.50 \\
\hline Pengajar 5 & 3.67 \\
\hline Pengajar 6 & 4.00 \\
\hline
\end{tabular}

\section{Gaya Sikap dan Perilaku}

Hasil evaluasi reaksi peserta terhadap seluruh unsur penilaian Gaya Sikap dan Perilaku dapat dijelaskan pada Tabel 11.

Tabel 11. Gaya Sikap dan Perilaku

\begin{tabular}{ll}
\hline Pengajar & Gaya Sikap dan Perilaku \\
\hline Pengajar 1 & 3.92 \\
\hline Pengajar 2 & 3.91 \\
\hline Pengajar 3 & 3.92 \\
\hline Pengajar 4 & 3.67 \\
\hline Pengajar 5 & 4.00 \\
\hline Pengajar 6 & 4.00 \\
\hline
\end{tabular}

Pada skala interpertasi analisis data, secara keseluruhan item pernyatan menunjukkan nilai berada di antara skala 3.5-4, sehingga dapat dinyatakan bahwa para peserta memiliki persepsi sangat baik dari Indikator Gaya Sikap dan Perilaku.

\section{Kerapihan Berbusana}

Hasil evaluasi reaksi peserta terhadap seluruh unsur penilaian Kerapihan dalam berbusana dapat dijelaskan pada Tabel 12. Pada skala interpertasi analisis data, secara keseluruhan item pernyatan menunjukkan nilai berada di antara skala 3.5-4, sehingga dapat dinyatakan bahwa para peserta memiliki persepsi sangat baik dari Indikator Kerapihan Berbusana.

Tabel 12. Kerapihan Berbusana

\begin{tabular}{ll}
\hline Pengajar & Kerapihan Berbusana \\
\hline Pengajar 1 & 3.92 \\
\hline Pengajar 2 & 3.91 \\
\hline Pengajar 3 & 3.92 \\
\hline Pengajar 4 & 3.67 \\
\hline Pengajar 5 & 4.00 \\
\hline Pengajar 6 & 4.00 \\
\hline
\end{tabular}

\section{Ketepatan Waktu, Kehadiran dan Penyajian Materi}

Hasil evaluasi reaksi peserta terhadap seluruh unsur penilaian Ketepatan Waktu, Kehadiran dan Penyajian Materi dapat dijelaskan pada Tabel 13. Pada skala interpertasi analisis data, secara keseluruhan item pernyatan menunjukkan nilai berada di antara skala 
3.5-4, sehingga dapat dinyatakan bahwa para peserta memiliki persepsi sangat baik dari Indikator Ketepatan Waktu, Kehadiran dan Penyajian Materi.

Tabel 13. Ketepatan Waktu, Kehadiran dan Penyajian Materi

\begin{tabular}{lc}
\hline Pengajar & $\begin{array}{l}\text { Ketepatan Waktu, Kehadiran dan } \\
\text { Penyajian Materi }\end{array}$ \\
\hline Pengajar 1 & 3.92 \\
\hline Pengajar 2 & 3.94 \\
\hline Pengajar 3 & 3.92 \\
\hline Pengajar 4 & 3.83 \\
\hline Pengajar 5 & 3.67 \\
\hline Pengajar 6 & 4.00 \\
\hline
\end{tabular}

\section{Kerjasama antar Pengajar}

Hasil evaluasi reaksi peserta terhadap seluruh unsur penilaian Kerjasama antar Pengajar dapat dijelaskan pada Tabel 14. Pada skala interpertasi analisis data, secara keseluruhan item pernyatan menunjukkan nilai berada di antara skala 3.5-4, sehingga dapat dinyatakan bahwa para peserta memiliki persepsi sangat baik dari Indikator Kerjasama antar Pengajar.

Tabel 14. Kerjasama antar Pengajar

\begin{tabular}{ll}
\hline Pengajar & Kerjasama antar Pengajar \\
\hline Pengajar 1 & 4.00 \\
\hline Pengajar 2 & 3.87 \\
\hline Pengajar 3 & 3.92 \\
\hline Pengajar 4 & 3.67 \\
\hline Pengajar 5 & 3.67 \\
\hline Pengajar 6 & 4.00 \\
\hline
\end{tabular}

\section{Pembahasan}

Berdasarkan hasil penelitian menunjukan bahwa unsur kualitas modul dirataratakan diperoleh nilai 3.41 yang berarti dapat dikategorikan baik. Maknanya adalah bahwa kualitas modul yang sudah digunakan saat ini menurut responden sudah sangat relevan atau memadai. Namun apabila akan dilakukan review terhadap kualitas modul agar lebih difokuskan pada aspek materi dalam modul sesuai dengan target kompetensi yang ditetapkan karena memperoleh penilaian yang paling rendah. Perbaikan terhadap kualitas modul harus menyentuh seluruh aspek yang ada, terutama pada aspek materi dalam modul sesuai dengan target kompetensi yang ditetapkan, yang memperoleh nilai terendah.

Sebagaimana penjelasan tersebut, maka materi dalam modul sesuai dengan target kompetensi yang ditetapkan pada Diklat Penguatan Kepala sekolah (PKS) yang digunakan saat ini masih perlu diperbaiki. Materi dalam modul mempunyai peran penting dalam proses pembelajaran di kelas karena menjadi acuan yang digunakan oleh widyaiswara untuk menyampaikan materi kepada peserta diklat. Bagi widyaiswara, materi menjadi acuan yang diserap isinya sehingga dapat menjadi pengetahuan, sedangkan bagi peserta diklat, materi dapat digunakan sebagai media untuk proses 
belajar secara mandiri. Setelah selesai mengikuti diklat, peserta dapat membuka kembali bahan ajar diklatnya untuk mengumpulkan kembali informasi yang sudah diperoleh saat mengikuti diklat.

Perlu diketahui bahwa materi berpengaruh terhadap kualitas hasil belajar (Sugiarti, 2013) sehingga dapat dipastikan bahwa kualitas modul merupakan satu hal yang sangat penting dalam keberhasilan penyelenggaraan diklat. Semakin baik kualitas modul maka semakin baik pula kualitas hasil belajar peserta diklat. Sebaliknya, apabila kualitas modul dinilai masih kurang maka kualitas hasil belajar juga akan kurang berkualitas. Perbaikan mengenai kualitas modul lebih diupayakan dari sisi substansi. Substansi modul merupakan pokok-pokok uraian untuk mencapai standar kompetensi yang ingin dicapai dalam proses pembelajaran. Oleh sebab itu, substansi modul harus disusun sesuai dengan standar. Agar kualitas modul ini dapat disusun lebih efektif untuk mencapai tujuan pembelajaran maka perbaikan kualitas bahan ajar perlu mengacu pada sisi ketepatan isi, kedalaman isi, dan proporsi isi antara penjelasan teori dan praktik. Ketepatan isi merupakan keabsahan bahan ajar sesuai dengan fakta sebenarnya, sesuai dengan praktik yang ada di lapangan. modul yang sudah terlalu lama juga perlu disesuaikan kembali dengan kondisi faktual dan relevansinya dengan kegiatan diklat PKS yang berkembang saat ini.

Perkembangan teknologi dan informasi yang semakin maju membuat banyak secara keseluruhan diperoleh Rata rata respon peserta yaitu Penguasaan Materi (3.93), Sistematika Penyajian (3.89), Kemampuan Menyajikan (Berorientasi HOTS) (3.86), Relevansi Materi dengan Tujuan (3.89), Penggunaan metode pembelajaran (3.84), Penggunaan media pembelajaran (3.83), Penggunaan Bahasa (3.87) Nada dan suara(3.89) Cara dan ketepatan menjawab pertanyaan peserta (3.86) Kemampuan memotivasi peserta (3.86), Gaya sikap, dan perilaku (3.90), Kerapihan dalam berbusana/ berpenampilan (3.93) perubahan termasuk dalam kegiatan diklat PKS, sehingga perlu dipastikan kembali ketepatan isi baik dari sisi teoretis maupun praktis sesuai kondisi kekinian.

Peserta Diklat Diklat Penguatan Kepala sekolah (PKS) memiliki latar belakang yang heterogen, baik dari segi umur maupun pengalaman sebagai kepala sekolah. Sesuai dengan fakta tersebut maka kedalaman isi bahan ajar juga harus mengakomodir perbedaan perbedaan tersebut. Isi bahan ajar dapat lebih substantif dengan menyajikan praktik-praktik dalam kegiatan pelatihan melalui studi kasus sebagai bahan diskusi peserta.

Diklat Penguatan Kepala sekolah (PKS) merupakan media bagi peserta untuk memenuhi persyaratan jabatan. Dalam rangka mewujudkan hal tersebut, bahan ajar didesain agar widyaiswara dan peserta lebih banyak melaksanakan praktik. Melalui praktik, peserta akan ikut terlibat dan memperoleh pengalaman langsung yang dapat bermanfaat baginya saat turun ke lapangan untuk melaksanakan tugasnya sebagai kepala sekolah.

\section{SIMPULAN}

Rata-rata respon peserta Diklat Penguatan Kepala sekolah (PKS) pada unsur Evaluasi Pengajar dan Ketepatan waktu, kehadiran, penyajian materi (3.92) Dan Rata rata keselurahan respon peserta yaitu 3,61. 
Analisis data, secara keseluruhan item pernyataan menunjukkan nilai berada di antara skala 3.5-4, sehingga dapat dinyatakan bahwa para peserta memiliki persepsi sangatbaik terhadap seluruh Pengajar.

\section{REFERENSI}

Arikunto, S. (2002). Dasar-dasar evaluasi pendidikan. Jakarta: Bumi aksara.

Arikunto, S. (2010). Prosedur penelitian: Suatu pendekatan praktik. Jakarta: Rineka Cipta.

Bagiyono. (2018). Jurnal evaluasi pelatihan teknik mengajar berdasarkan model empat level evaluasi pelatihan. Yogyakarta: STTN Batan.

Tim Bahasa Balai Pustaka. (1999). Kamus Besar Bahasa Indonesia. Jakarta: Balai Pustaka.

Basri, D. H. (2013). Landasan pendidikan. Bandung: Pustaka Setia.

Depdiknas. (2003). Undang-undang Nomor 20 Tahun 2003. Jakarta: Depdiknas.

Kaswan. (2011). Pelatihan dan pengembangan. Bandung: Alfabeta.

Kirkpatrick, D. K. (2008). Evaluating training programs: the Four levels. San Fransisco, California: Berret- Koehler Publisher, Inc.

Maya, Y. (2020). Penggunaan blended learning pada pembelajaran era industri 4.0. Bahastra: Jurnal Pendidikan Bahasa dan Sastra Indonesia, 4(2), 31-38.

Philips, J. J. (1997). Handbook of Training Evaluation and measurement methods. Houston: Gulf Publishing.

Purwanto. (2011). Evaluasi hasil belajar. Yogyakarta: Pustaka Belajar.

Safitri, A., \& Yusiyaka, R. A. (2020). Pengelolaan diklat penguatan kepala sekolah untuk meningkatkan kompetensi kepala sekolah (studi kepala sekolah SDN di Kabupaten Sukabum1). JURNAL OBOR PENMAS, 3(1), 203-213.

Sugiono. (2015). Metode penelitian kuantitatif, kualitatif dan R \& D. Bandung: Alfabeta.

Sukardi. (2003). Metodologi Penelitian Pendidikan. Yogyakarta: Bumi aksara.

Wirawan. (2012). Evaluasi teori, model, standar, aplikasi dan profesi. Jakarta: Raja Grafindo Persada. 